\title{
Study on Dynamic Response of Fiber-Reinforced Plastic Float for Light Seaplane
}

\author{
Yoshio Aoki ${ }^{1}$, Akihisa Tabata ${ }^{1}$, Ryo Goto ${ }^{1}$ and Goichi Ben ${ }^{2}$ \\ 1. Department of Precision Machinery Engineering, Nihon University, Funabashi, Chiba 274-8501, Japan \\ 2. Department of Mechanical Engineering, Nihon University, Narashino, Chiba 275-8575, Japan
}

\begin{abstract}
The marine area of Japan, including territorial waters and the exclusive economic zone, is the sixth largest in the world at about 4,470,000 $\mathrm{km}^{2}$. Therefore, it is becoming necessary to establish appropriate means of transportation other than ships in order to utilize the area efficiently. In this respect, ultra-light seaplanes are attracting attention from the viewpoint of protecting the natural environment. Accordingly, JRPS (Japan Reinforced Plastics Society) is currently developing FRP (fiber-reinforced plastic) floats for such planes. In this study, we conducted simulations of seaplane behavior during alighting by using the smoothed particle hydrodynamics method, which is one of the functions in the PAM-CRASH solver, and we present the observed trend in the vertical acceleration of the floats as a first step toward deriving the impact force from analytical data.
\end{abstract}

Key words: Dynamic response, FRP float, smoothed particle hydrodynamics, seaplane, structural analysis, airworthiness.

\section{Introduction}

The marine area of Japan, including territorial waters and the exclusive economic zone, amounts to about 4,470,000 $\mathrm{km}^{2}$, which is the sixth largest in the world. Accordingly, seaplanes are increasingly attracting attention due to the demand for establishing new means of appropriate transportation other than ships which can efficiently utilize the vast Japanese marine resources.

If routes which are necessary for takeoff and alighting of seaplanes can be secured, seaplanes could prove to be economical since they do not require the immense resources and are necessary for building airports, and it has also been pointed out that they could provide a solution to certain social problems, for example, by preventing environmental damage inflicted by land reclamation in coastal areas and providing a means for emergency transportation of goods to remote islands at times of disaster. However, the floats used in lightweight planes at present are

Corresponding author: Yoshio Aoki, Dr., professor, research fields: safety design engineering and structural analysis. made of metal or rubber, which are not ideal in terms of weight and resistance to corrosion. For this reason, we have started development of FRP (fiber-reinforced plastic) floats shown in Fig. 1.

In addition to an excellent strength-to-weight ratio and specific rigidity, FRP also exhibits high resistance to corrosion and impact, and, therefore, it can serve as appropriate material for floats, which repeatedly come in contact and detach from the water surface during takeoff and alighting. In addition, further weight reduction and corrosion and impact resistance improvements can be achieved by using a core made of a porous material sandwiched between FRP surfaces, allowing for the development of highly efficient seaplane floats.

In this study, we conducted alighting experiments and numerical simulations on the basis of the alighting positions specified in the Airworthiness Standards [1], and we compared the alighting behavior and vertical acceleration response of seaplane floats. Furthermore, we used strain gauges to measure the stress and its distribution generated in the floats by the impact force during alighting, and we examined the dynamic 
response and the impact force used in designing seaworthy FRP floats.

The stress measurements in the current experiment are ongoing, and detailed results will be reported at the time of presenting this paper.

The evaluated FRP floats were HY03 floats developed for seaplanes under a seaplane development project undertaken by the JRPS (Japan Reinforced Plastics Society).

\section{Composition of Floats}

A sandwich structure consisting of a porous material at the core and glass FRP (GFRP (glass cloth/unsaturated polyester resin)) at the surface was used for the FRP float structure. The shape and dimensions of the FRP floats (Table 1 and Fig. 2) are shown together with the details about the structural materials $[2,3]$ :

(1) core material: polystyrene;

(2) surface material: glass cloth:

- thickness of a single layer covering the entire unit: $0.25 \mathrm{~mm}$;

- thickness of three layers at the keel: $0.75 \mathrm{~mm}$ (a total of four layers);

- thickness of two layers at the upper surface: $0.5 \mathrm{~mm}$ (a total of three layers);

(3) bulkhead plating: glass cloth-GFRP plates consisting of 12 layers for 3-mm thickness were installed 1,500, 2,000 and 2,700 $\mathrm{mm}$ from the front;

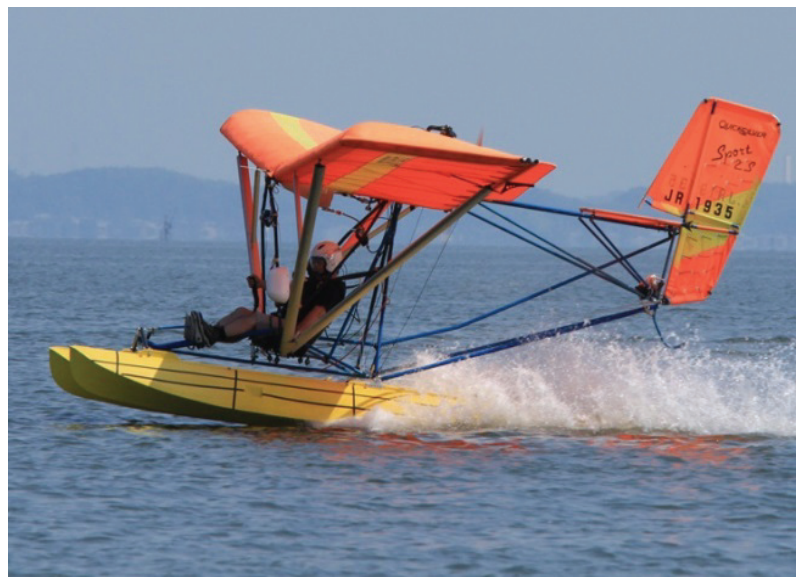

Fig. 1 Lightweight seaplane with FRP floats.
(4) resin: unsaturated polyester resin;

(5) weight: a single float weighs $32 \mathrm{~kg}$ (including the parts for attaching supporting structures and brackets).

\section{Alighting Impact Experiment}

Alighting impact experiments were conducted by wide water tank with wave-maker at Ocean Architecture Laboratory in Department of Oceanic Architecture and Engineering of Nihon University, AS shown in Fig. 3. In the experiments, a lightweight seaplane equipped with FRP floats was dropped from a height of 1,200 $\mathrm{mm}$, and the impact exerted by the water surface on the floats for front, central and rear alighting was measured, as specified in the Airworthiness Standards [1]. At this stage, the dynamic response of the FRP floats was also measured by accelerometers installed at two points on the upper surface of both floats. This measurement was used to verify the validity of the numerical results and the dynamic response for the still water is compared with

Table 1 Dimensions of float.

\begin{tabular}{llll}
\hline Length $(\mathrm{mm})$ & Width $(\mathrm{mm})$ & Height $(\mathrm{mm})$ & $\begin{array}{l}\text { Displacement } \\
(\mathrm{L})\end{array}$ \\
\hline 4,000 & 523 & 480 & 443 \\
\hline
\end{tabular}

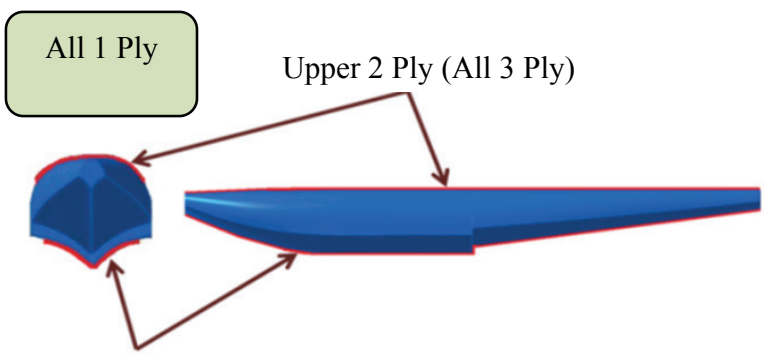

Keel 3 Ply (All 4 Ply)

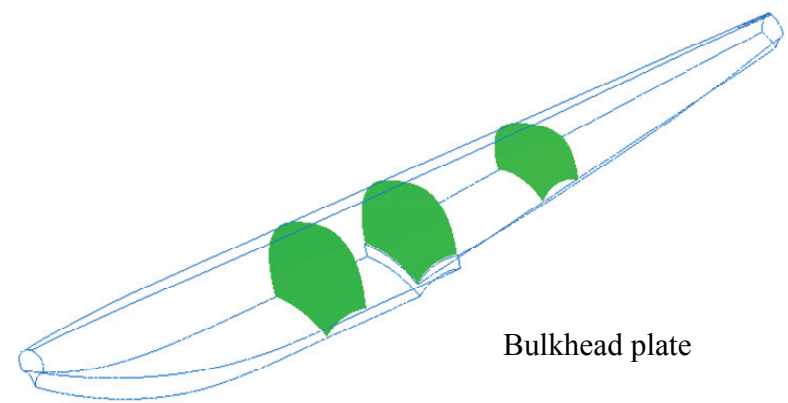

Fig. 2 FRP float model. 


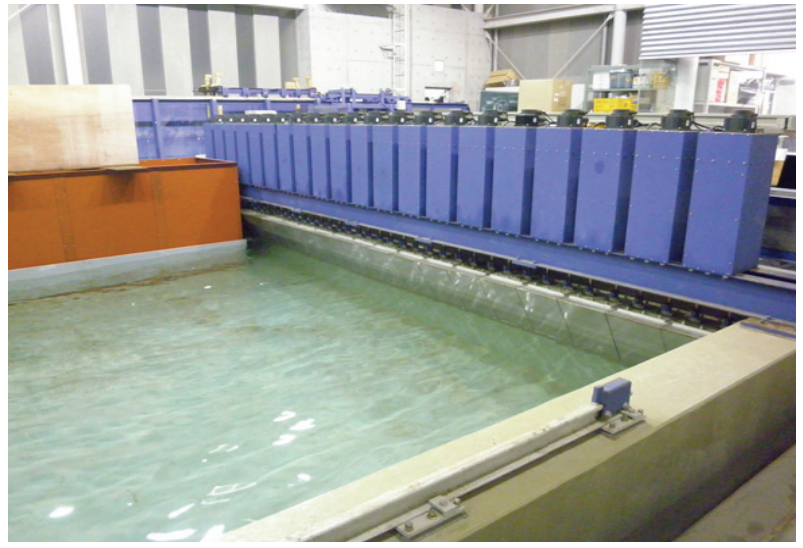

Fig. 3 One-directional wave-maker.

Table 2 Experiment condition under the swell.

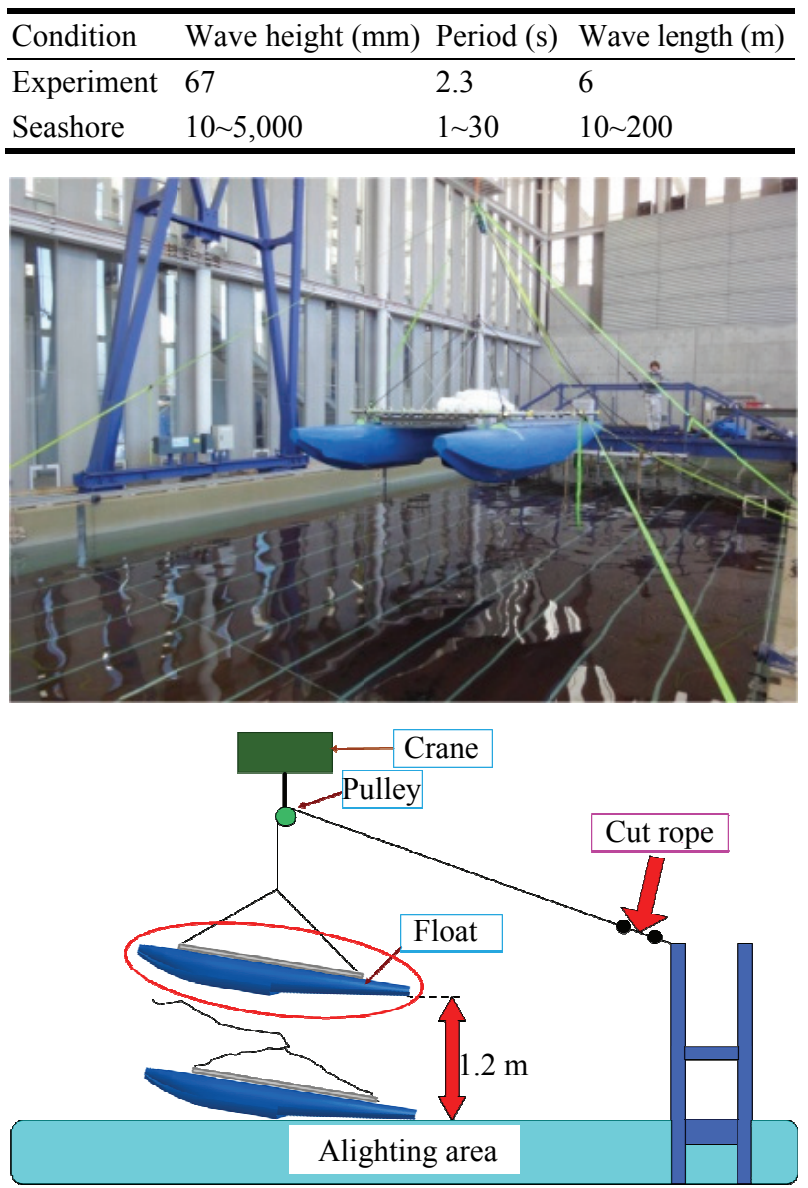

Fig. 4 Experimental equipment.

those under the swell. Table 2 shows the condition of alighting experiment under the swell $[4,5]$.

\section{Experimental Results}

In this experiment, we used the lightweight seaplane model shown in Fig. 4 (total weight: $168.3 \mathrm{~kg}$ ). And, although the angle during alighting is generally considered to be $5^{\circ} \sim 7^{\circ}$, taking into consideration the possibility for alighting in rough water, the alighting angle in this case was set to $10^{\circ}$ forward and $10^{\circ}$ backward, as shown in Fig. 5. Furthermore, in the alighting impact experiments, since the speed in the direction of motion cannot be simulated, the sinking speed and the speed in the direction of motion were combined. In the free fall speed $\left(1.2 V_{s} \cdot \sin (\theta)+\right.$ $\left.V_{d} \cdot \cos (\theta)\right)$ corresponding to the speed of impact with the water surface, the speed in the direction of motion $V_{s}$ was set to $65 \mathrm{~km} / \mathrm{h}$ (equal to $17.7 \mathrm{~m} / \mathrm{s}$ ) as defined by

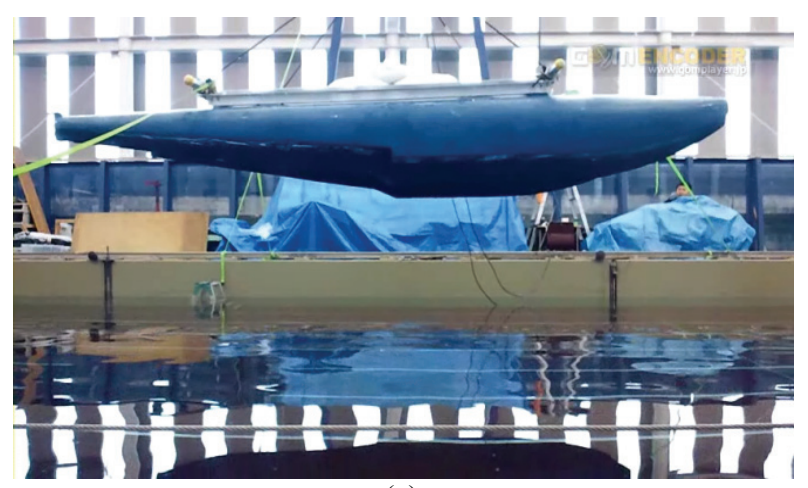

(a)

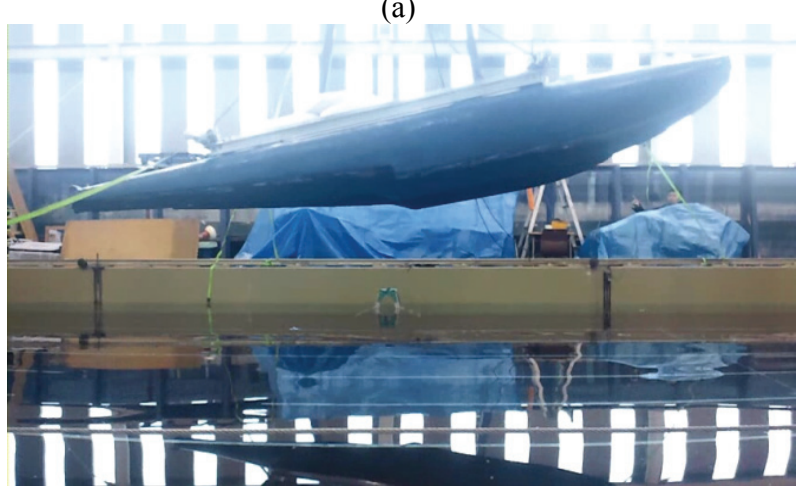

(b)

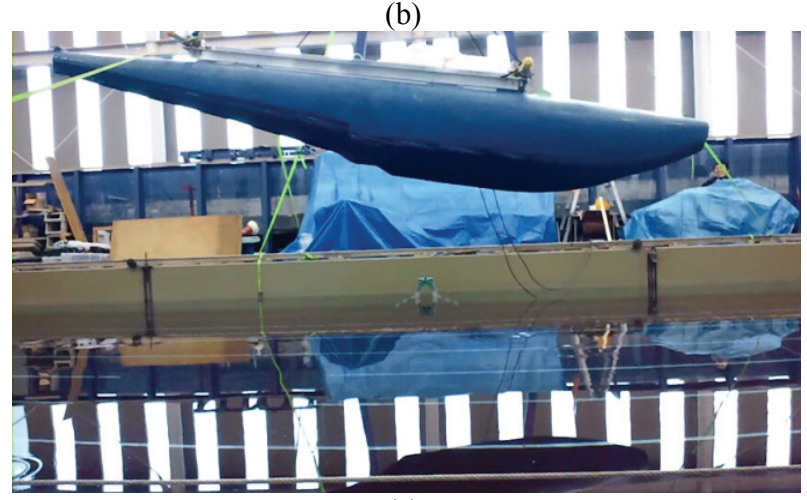

(c)

Fig. 5 Water landing positions: (a) central alighting; (b) front alighting; (c) rear alighting. 
the Ministry of Land, Infrastructure, Transport and Tourism. Lastly, since the sinking speed $V_{d}$ is commonly taken as $2 \sim 4 \mathrm{ft} / \mathrm{s}$ (equal to $1.22 \sim 2.44 \mathrm{~m} / \mathrm{s}$ ) for civilian aircrafts, the experiments were conducted by setting the value of $V_{d}$ to $4 \mathrm{ft} / \mathrm{s}$. As the results of this calculation, the alighting impact test was carried out by landing distance of $1.2 \mathrm{~m}$.

Table 3 presents the measurement results for the maximum vertical acceleration obtained at the impact of the floats during water landing for still water.

Fig. 6 shows the time history of float acceleration and strain for the still water and swell conditions. For still water, maximum acceleration and the strain are measured at the same time and larger than those for swell condition. Maximum strain under the swell was about half in the case of the still water.

The measured strain under the swell would never be greater than maximum strain for still water with the change of the top of swell, as shown in Fig. 7.

\section{Numerical Analysis}

In the analytical model, the floats, supporting parts, weights, alighting areas and boundary walls were created in CAD (computer-aided design) software (CATIA-V5) and divided into elements with auto meshersoftware (HyperMesh 10.0). The analytical model in Fig. 8 was constructed by applying SPH (smoothed particle hydrodynamics), which is one of the options in the dynamic explicit finite element method solver PAM-CRASH, to the alighting areas and regarding the water continuum as a collection of particles.

Next, the material properties used in the analytical model are shown in Table 4. The numerical analysis was conducted by using elastic shell elements for the GFRP of the floats, elastoplastic solid elements for the porous polystyrene core material and rigid shell elements for the boundary walls, the attachment structures of the floats and the weights.

Furthermore, the analysis conditions were set as follows by considering the alighting impact experiment:

(1) The state immediately before alighting when the floats were dropped was modeled, assigning a free fall speed of $-4.44 \mathrm{~m} / \mathrm{s}$;

Table 3 Maximum vertical acceleration.

\begin{tabular}{lll}
\hline Water landing position & Left float & Right float \\
\hline Central alighting $(\mathrm{G})$ & 13.67 & 12.27 \\
Front alighting $(\mathrm{G})$ & 13.31 & 12.30 \\
Rear alighting $(\mathrm{G})$ & 12.34 & 13.35 \\
\hline
\end{tabular}

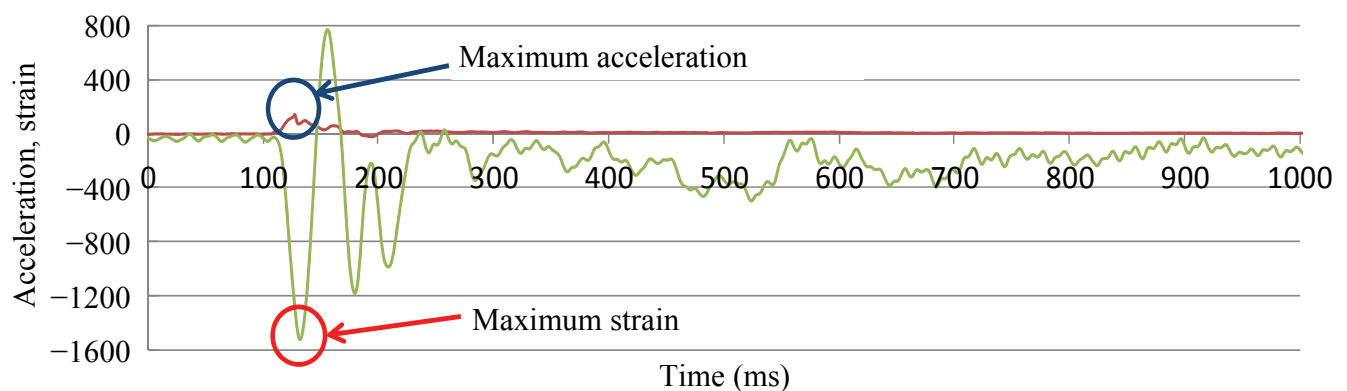

(a)

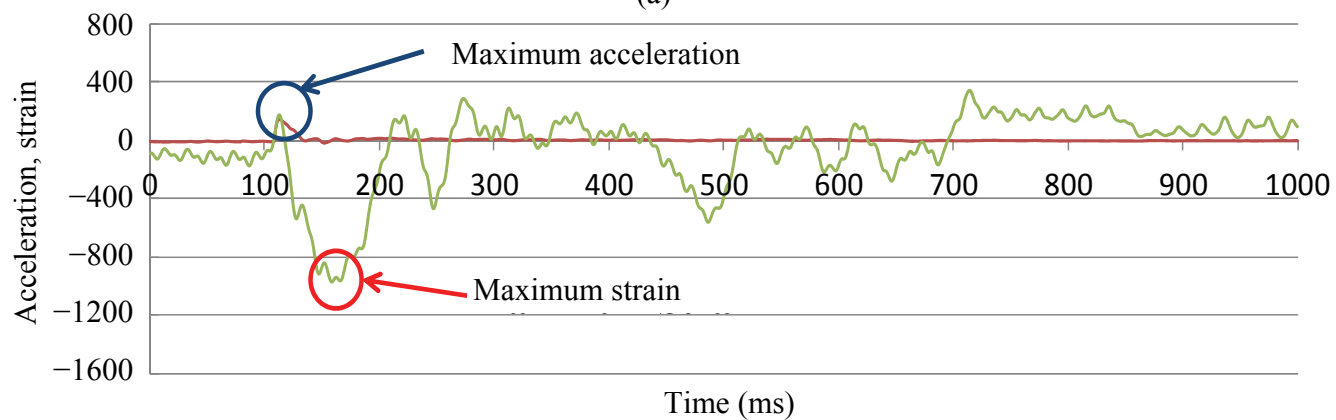

(b)

Fig. 6 Dynamic response of alighting acceleration and strain of the float for: (a) still water; (b) the swell. 

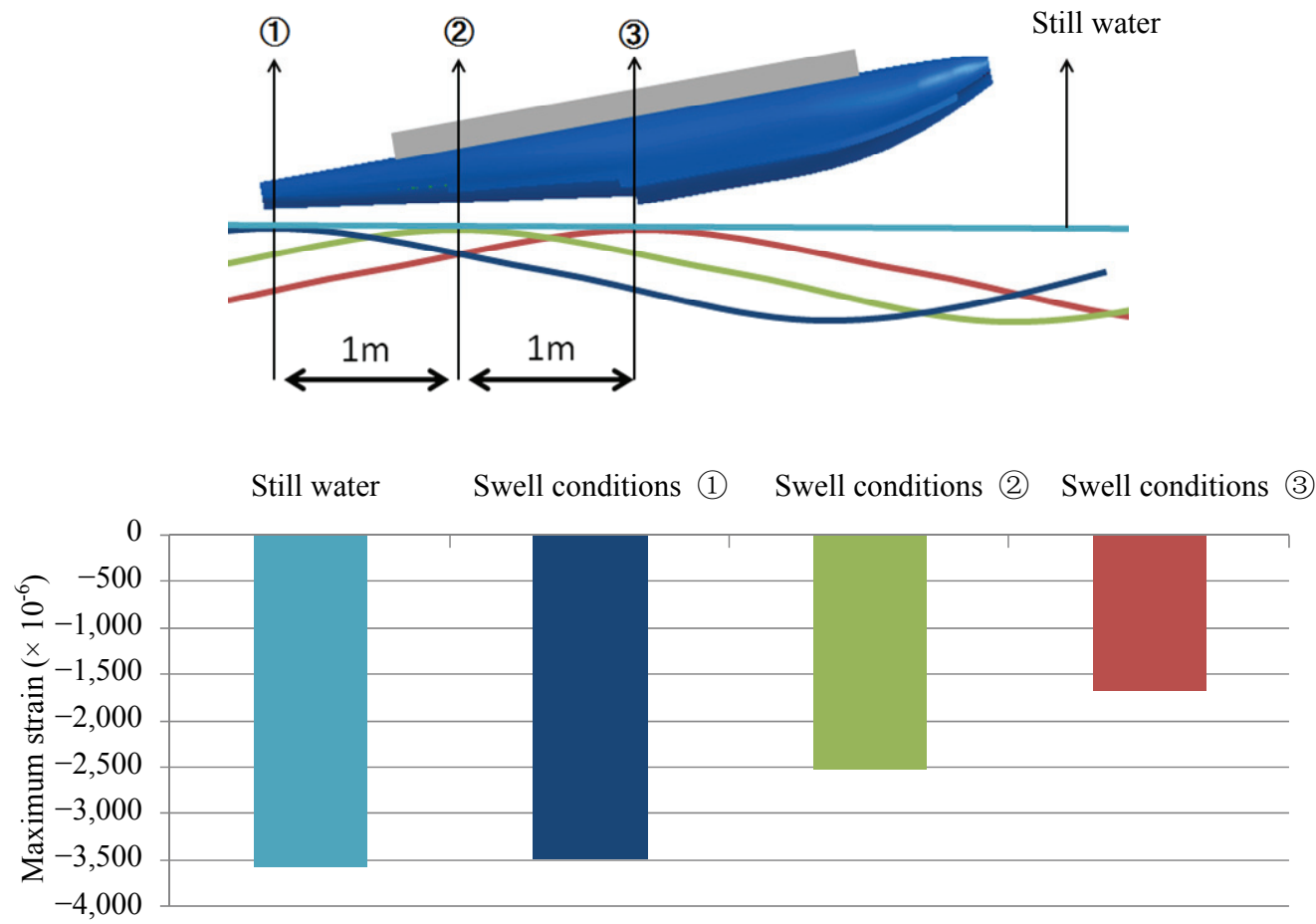

Fig. 7 Maximum strain of the alighting experiment for still water and various swell conditions.

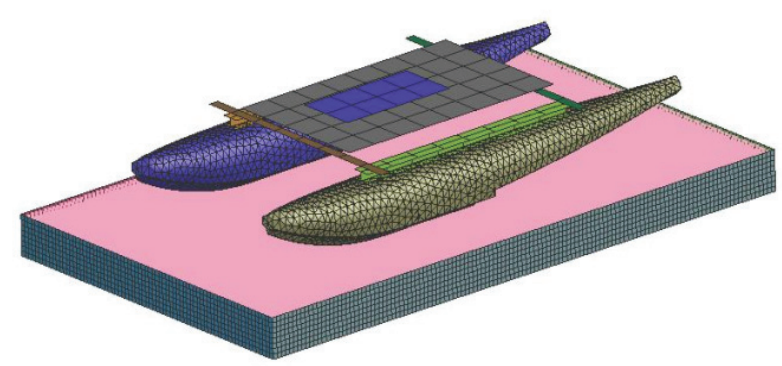

Fig. 8 Analytical model.

Table 4 Material properties.

\begin{tabular}{lllll}
\hline Property & GFRP & $\begin{array}{l}\text { Polystyrene } \\
\text { foam }\end{array}$ & Mount & Weight \\
\hline$E(\mathrm{GPa})$ & 43 & 0.025 & 207 & 207 \\
Poisson ratio & 0.28 & 0.3 & 0.3 & 0.3 \\
\hline $\begin{array}{l}\rho \times 10^{-6} \\
\left(\mathrm{~kg} / \mathrm{mm}^{3}\right)\end{array}$ & 1.70 & 0.012 & 3.95 & 2.00 \\
\hline
\end{tabular}

(2) The combined weight of the weights and the structure equipped with floats $(32 \mathrm{~kg} \times 2)$ was set to $232.3 \mathrm{~kg}$;

(3) In SPH, the five surfaces other than the ones involved in the alighting were surrounded with rigid walls in the form of shell elements, thus restricting the overall degrees of freedom;

(4) For understanding the behavior of the floats during alighting, nodes were set at roughly the same locations as during the experiment;

(5) Dynamic transient response analysis was conducted for $150 \mathrm{~ms}$ with a time step of $0.04 \mathrm{~ms}$.

\section{Comparisons of Experimental and Analytical Results}

The alighting behavior in the experiment and the analysis can be seen in Fig. 9, and Fig. 10 shows the time history response curve of the vertical acceleration at the moment of alighting of the floats. The vertical acceleration standards recommended by SAE (Society of Automotive Engineers) were referred to in both the analytical and the experimental results, and in this case we used CFC60 (equivalent to $-40 \mathrm{~dB} / \mathrm{oct}$ ( $\mathrm{dB}$ per octave) cutoff $100 \mathrm{~Hz}$ ).

We found that the maximum vertical response acceleration was $13.31 \mathrm{G}$ in the experiment and $16.21 \mathrm{G}$ in the analysis, thus showing a slight difference, but the time history responses for the acceleration were in close agreement [6]. Furthermore, we confirmed that the trends observed during front and rear alighting were the same as those presented above. 


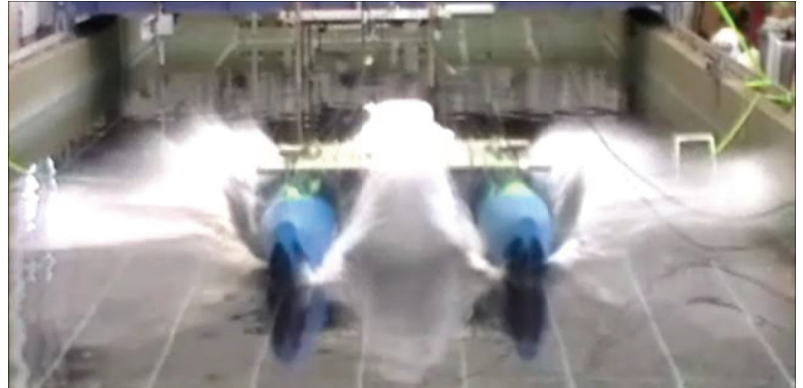

(a)

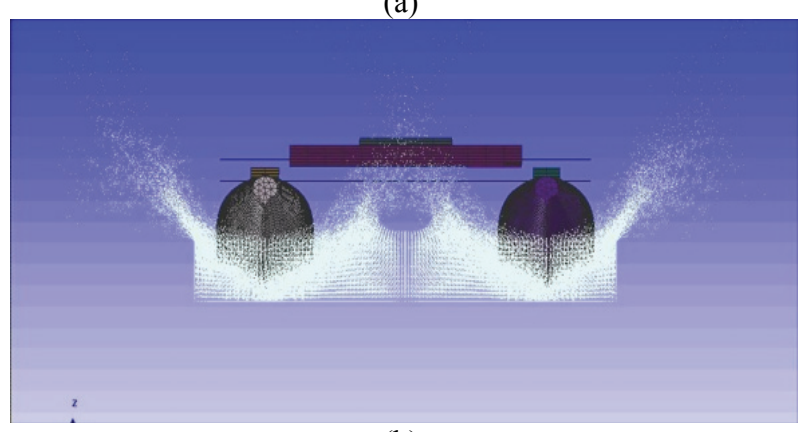

(b)

Fig. 9 Alighting behavior: (a) experiment; (b) analysis.

longitudinal stress distribution of the FRP float

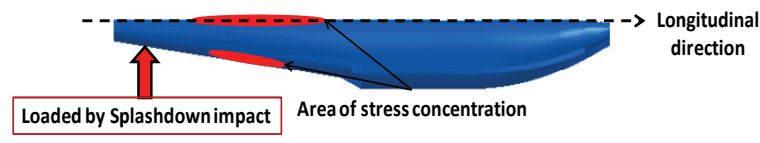

\section{Bottom of float}

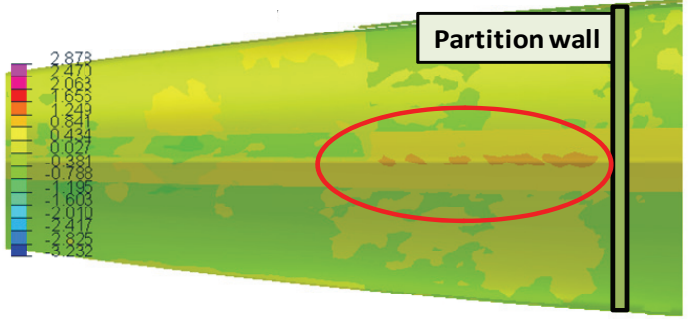

Tension stress

\section{Upper surface of float}

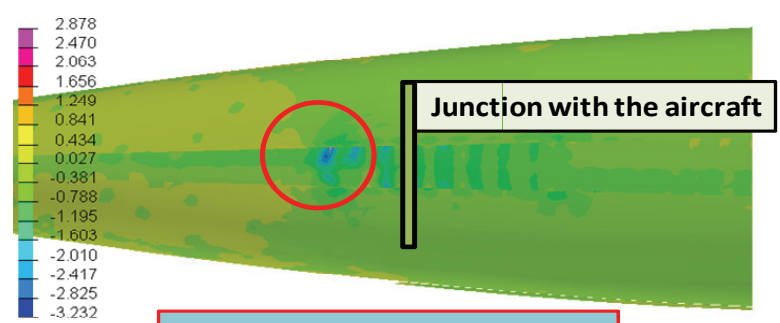

\section{Compression stress}

(a)
Next, Fig. 11 shows the results of numerical analysis of the initiation stress in the case of rear alighting, where the response acceleration of the FRP floats was high. Fig. 11a shows the abovementioned stress distribution in lengthwise direction of the floats as obtained in the analytical model, and Fig. 11b shows the stress distribution in crosswise direction. The maximum stress was generated in the vicinity of joint

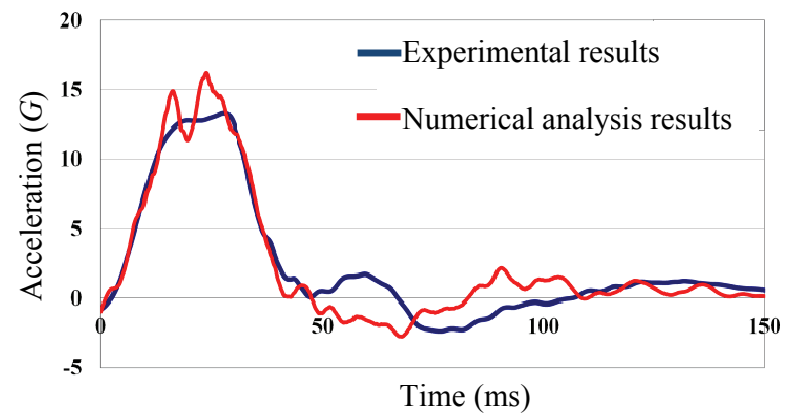

Fig. 10 Acceleration in central alighting (left float).

width stress distribution of the FRP float

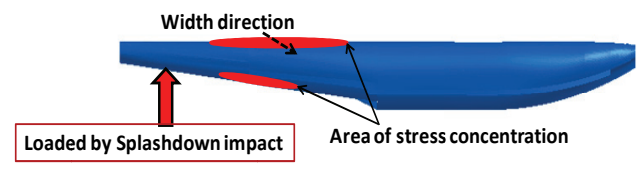

\section{Bottom of float}

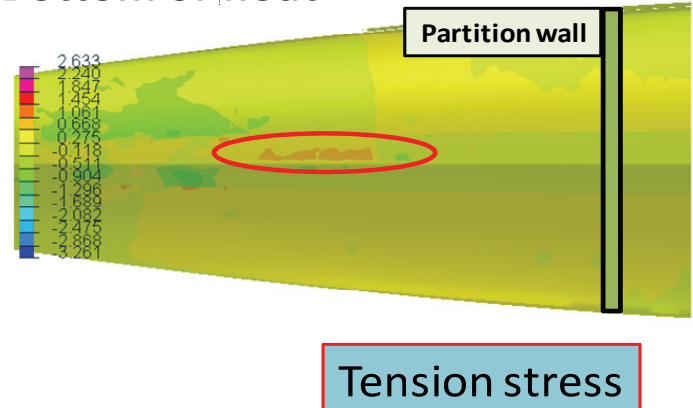

\section{Upper surface of float}

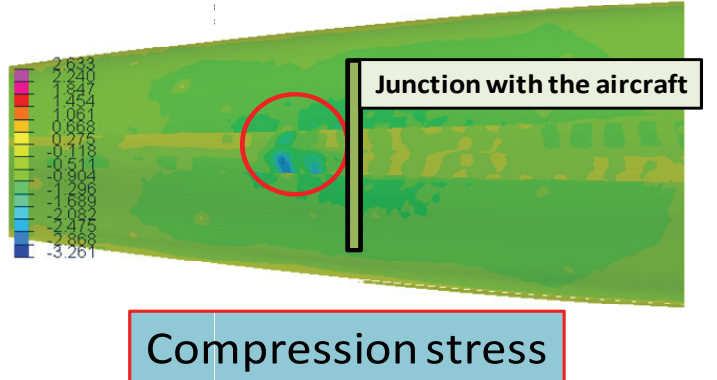

(b)

Fig. 11 Stress distribution by the numerical results: (a) lengthwise stress distribution of the float; (b) crosswise stress distribution of the float. 


\section{longitudinal strain at keel section Strain at junction with the aircraft}
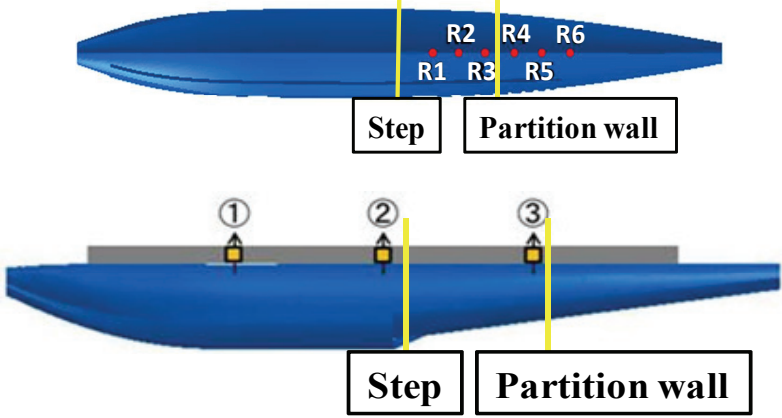
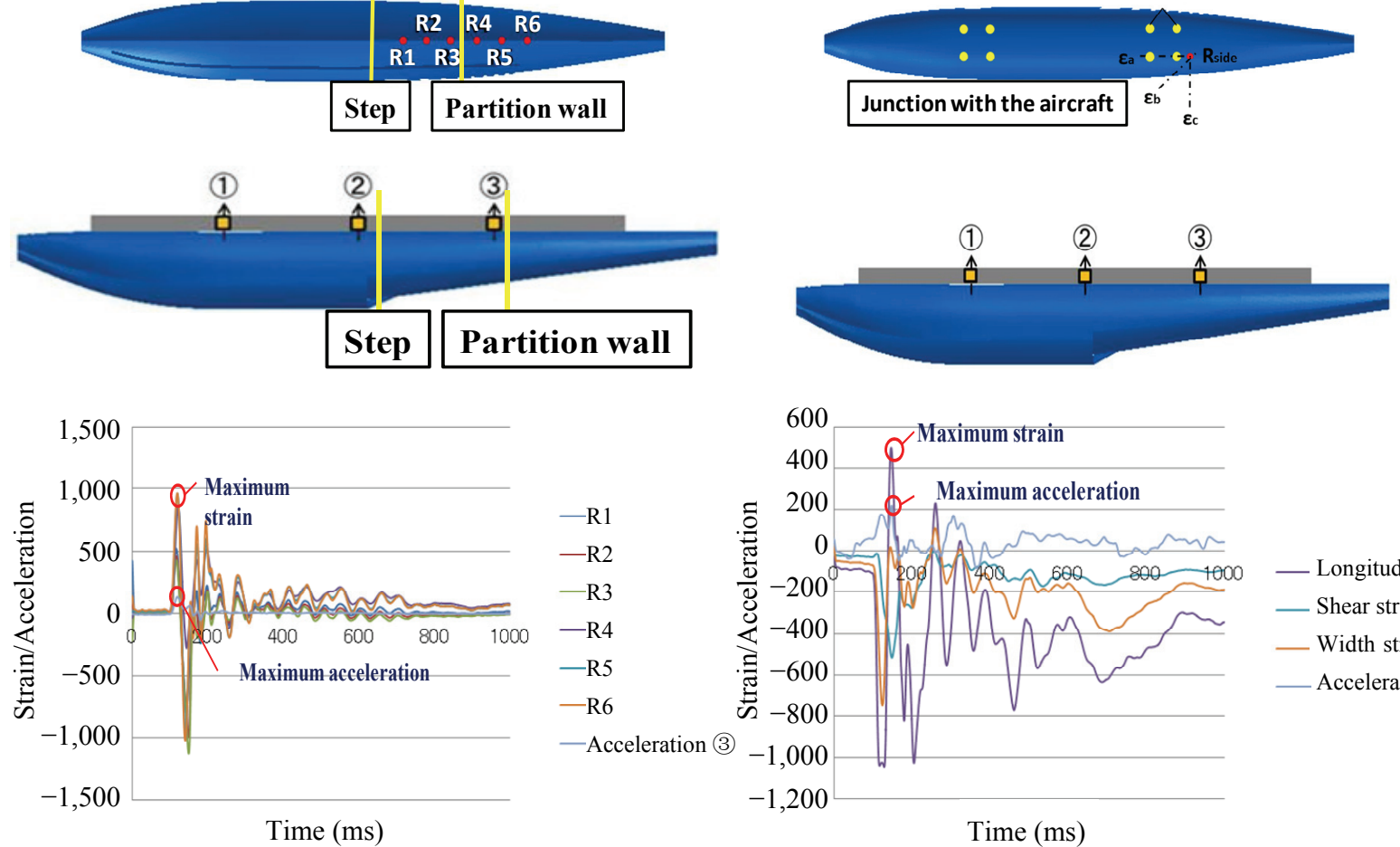

(a)

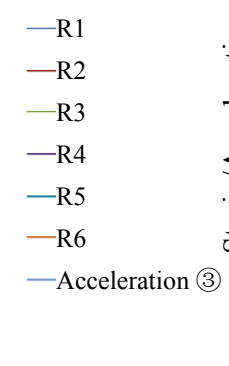

$-1,200$

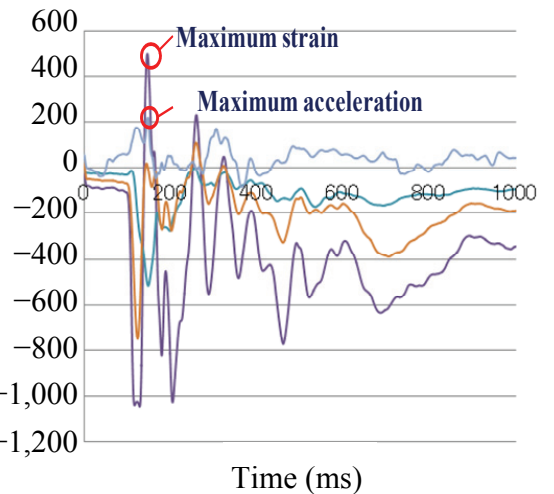

(b)

Fig. 12 Measured dynamic response strain of FRP float: (a) experimental strain in lengthwise direction of the base of the FRP float in the alighting impact experiment; (b) experimental strain around the upper surface connection with the aircraft body in the alighting impact experiment.

elements connecting the rear parts of the floats with the body of the aircraft, as well as in the vicinity of the bulkhead at the base, and the computational results showed high tensile stress at the base and high compressive stress at the upper surface of the floats during alighting. Considering this stress distribution, strain measurements in the alighting impact experiment were taken at seven locations at the joints where the floats are connected to the aircraft body and in the vicinity of the bulkhead, and the response strain was measured in an alighting impact experiment.

Fig. 12 shows the time history response for the measured strain for each part of the FRP float in the alighting impact experiment. Fig. 12a shows the dynamic response of the strain in lengthwise direction in the vicinity of the bulkhead at the lower rear part of the FRP float, and the maximum value of the generated strain at R6, which was close to the location where the maximum stress was generated in the numerical analysis, was measured to be around $\pm 1,000 \times 10^{-6} \varepsilon$. Furthermore, Fig. $12 \mathrm{~b}$ shows the time history response in the vicinity of the joints connecting the upper surface of the FRP floats and the aircraft body, and, similarly to the numerical analysis results, the maximum value was higher than $-1,000 \times 10^{-6} \varepsilon$ on the compressive side. Since we measured the triaxial strain at the upper surface of the floats, the maximum principal stress is calculated from the measurement results, yielding a value of 42.1 $\mathrm{MPa}$ in the compression direction. This maximum value of the principal stress is rather small in comparison to the allowable stress of $270 \mathrm{MPa}$ for GFRP, and it is considered to possess sufficient durability with respect to repeated alighting.

\section{Conclusions}

Following points can be drawn from the study:

(1) In order to develop highly impact-resistant 
GFRP floats for seaplanes, we conducted numerical simulations and alighting impact experiments and elucidated the dynamic response characteristics and the locations of stress concentration in FRP floats during alighting;

(2) As a result of both performing numerical analysis and alighting impact experiments to examine the response acceleration generated when FRP floats with a sandwich structure impact the water surface, the results of the numerical analysis and those of the alighting impact experiments were found to be in close agreement, thus confirming the validity of the numerical analysis;

(3) The maximum value and the locations where dynamic response strain was generated in the FRP floats in each alighting position (front, central and rear) were examined by numerical analysis, and the validity of computational results was verified through an alighting impact experiment;

(4) Stress generated in the GFRP floats used in this experiment is sufficiently low in comparison to the allowable stress of FRP, and we confirmed the durability of the structure with respect to alighting impact.

In future work, we plan to investigate the appropriate shape for FRP floats for both alighting impact and takeoff performance. Furthermore, the resistance of FRP floats against wave impacts will be examined by conducting alighting impact experiments in the presence of waves.

\section{Acknowledgments}

We express our gratitude to all members of the seaplane development project at JRPS who participated in the preparation of the FRP float model used in this research.

\section{References}

[1] Ministry of Land, Infrastructure and Transport Civil Aviation Bureau, Aviation Safety Department. 2011. Airworthiness Standards. Tokyo: Ministry of Land, Infrastructure and Transport Civil Aviation Bureau, Aviation Safety Department.

[2] Itoh, H., Miyagi, C., Ookubo, T., Murata, K., Haruyama, H., and Kanno, T. 2007. A Design and Built of Wooden Floats for Micro-light-airplane. Vol. 1. Report for Tokyo Metropolitan College of Industrial Technology, 52-9.

[3] Itoh, H., Miyagi, C., Ookubo, T., Murata, K., and Haruyama, H. 2008. A Design and Built of Wooden Floats for Micro-light-airplane-2nd Report. Vol. 2. Report for Tokyo Metropolitan College of Industrial Technology, 55-63.

[4] Kawaguchi, K., Inomata, T., and Seki, K. 2013. Technical Note of the Port and Airport Research Institute, No.1265. Yokosuka: Port and Airport Research Institute.

[5] National Marine Research Institute. 2012. "Oceanic and Atmospheric Database." National Marine Research Institute. Accessed April 15, 2012. http://www.nmri.go.jp/wavedb/wave2.html.

[6] Nagata, T., Tabata, A., Aoki, Y., and Ben, G. 2012. "Study on Dynamic Response of Fiber-Reinforced Plastic Float for Light Seaplane." Presented at the 9th Joint Canada-Japan Workshop on Composites, Kyoto, Japan 